Dig Surg 2002;19:86-87

\title{
Introduction
}

\author{
L. Bonavina ${ }^{a}$ J J .B. van Lanschot ${ }^{\mathrm{b}}$ \\ aDepartment of Surgical Sciences, University of Milano, Italy; b Department of Surgery, Amsterdam, \\ The Netherlands
}

\section{Oesophageal Surgery}

The great majority of oesophageal resections are performed because of malignant disease. Because of advances in surgical technique and perioperative care, hospital mortality after oesophageal resection has decreased over the last decades from 29\% in the period 1953-1978 to $7.5 \%$ in the period $1990-2000$. Several studies have shown that centralization of oesophagectomies in dedicated centres might help to decrease hospital mortality [1]. The experience of the surgeon is a major factor influencing mortality rates after oesophagectomies.

Oesophageal resection implies a great surgical trauma in at least two (chest and abdomen) and frequently even three (chest, abdomen and neck) different compartments. Especially the combination of a thoracotomy and a laparotomy puts the patient at great risk for the development of serious postoperative (especially cardiopulmonary) complications. The transhiatal resectional technique has been developed to limit the surgical trauma, but has been criticised because of its supposedly limited oncological radicality.

Most surgeons consider the narrow gastric tube as the preferred organ for reconstruction. The oesophagogastric anastomosis can be made either in the neck or in the chest. On the one hand, a cervical anastomosis has a rela- tively high risk of leakage and benign stricture formation. On the other hand, a cervical dehiscence only rarely leads to a life-threatening mediastinitis, which is in contrast to an intrathoracic anastomosis.

Many different anastomotic techniques have been tested, including end-to-end versus end-to-side anastomosis, hand-sewn versus mechanical suturing, running versus interrupted suturing. Recently, it has been claimed that a side-to-side anastomosis has excellent outcome, with low leakage rate and low stricturing rate [2].

In this postgraduate course a patient was presented who developed severe postoperative complications due to delayed healing of a cervical anastomosis following oesophageal resection. Subsequently, a comprehensive review of the recent literature was presented by Prof. Lerut (Leuven, Belgium).

\section{Gastric Surgery}

Peptic ulcer hemorrhage (PUH) remains an important medical emergency. Mortality is still substantial and has remained stable over the past few decades, despite advances in diagnosis and therapy. During this period, the role of surgery in the management of PUH has dramatically changed. Endoscopic therapy has superseded surgery

\begin{tabular}{ll}
\hline KARGER & ○ 2002 S. Karger AG, Basel \\
Fax +4161306 1234 & $0253-4886 / 02 / 0192-0086 \$ 18.50 / 0$ \\
$\begin{array}{l}\text { E-Mail karger@karger.ch } \\
\text { www.karger.com }\end{array}$ & $\begin{array}{l}\text { Accessible online at: } \\
\text { www.karger.com/journals/dsu }\end{array}$
\end{tabular}

J.J.B. van Lanschot

Department of Surgery, Academic Medical Center, University of Amsterdam Meibergdreef 9

NL-1105 AZ Amsterdam (The Netherlands)

Tel. +31 20 5662766, Fax +3120 5669243, E-Mail j.j.vanlanschot@amc.uva.nl 
as the first-line method to stop ulcer bleeding. Nowadays, the aim of surgery is mostly confined to situations in which endoscopic therapy fails [3].

Adequate hemostasis can be obtained in more than $98 \%$ of the patients by experienced endoscopists [4]. This leads to a highly negative selection of the most complicated patients for surgical intervention. The optimal timing of operation and choice of surgical techniques remain the great challenges in today's surgical management of patients with PUH.

\section{References}

1 van Lanschot JJB, Hulscher JBF, Buskens CJ, Tilanus HW, ten Kate FJW, Obertop H: Hospital volume and hospital mortality for oesophagectomy. Cancer 2001;91:1574-1578.

2 Orringer MB, Marshall B, Jannettoni MD: Eliminating the cervical esophago-gastric anastomotic leak with a side-to-side stapled anastomosis. J Thorac Cardiovasc Surg 2000;119: 277-288.
3 Chung SCS, Li AKC: Helicobacter pylori and peptic ulcer surgery. Br J Surg 1997;84:1489_ 1490.

4 Lau JY, Sung JJ, Lam YH, et al: Endoscopic retreatment compared with surgery in patients with recurrent bleeding after initial endoscopic control of bleeding ulcers. N Engl J Med 1999; 340:751-756. 